\title{
Death from cancer at home: the carers' perspective
}

\author{
R V H Jones, J Hansford, J Fiske
}

\begin{abstract}
Objectives-To collect information from principal carers of people who had died at home with cancer; to identify areas of support which need improvement.

Design-Semistructured interviews with carers two to four months after the death.

Setting-38 general practices in the Exeter,

Torbay, and Plymouth health districts.

Subjects-207 carers.

Main outcome measures-Services received by carers and quality of support.

Results-161 of 207 patients were aged 60 or over. 88 carers were aged under 60,110 were $60-80$, and 9 were $>80$. Carers had difficulty in getting urgent professional help in only 15 out of 177 cases. 124 carers were not given advice on financial help and 174 were not told of support available from local charities. Although pain was well controlled, $25 \%$ of patients had no relief of other symptoms. Overall, 150 carers considered the support excellent, 45 good, 8 moderate, 2 poor, and 2 had no comment.

Conclusions-Although care has improved in recent years, health professionals need to give carers more advice about help available outside health services. Domestic help was often needed earlier. Better appreciation of carers' problems is needed.
\end{abstract}

\section{Introduction}

Since a working group of the Standing Medical Advisory Committee expressed the view in 1980 that the worst as well as the best terminal care can take place at home there have been major changes in the education of doctors and nurses regarding the needs of terminally ill people and in the services available.' Guidelines for good terminal care have been published..$^{23}$ In many parts of Britain hospices, support teams, and specialist nurses are now available to help primary health care teams. We interviewed the principal carers of people with cancer who had died at home in three Devon health districts during 1987-9 to identify aspects of care where deficiences still exist.

\section{Subjects and methods}

General practitioners in Exeter, Torbay, and Plymouth health districts had been asked to notify the department of people with cancer who had died at home as part of a larger study. ${ }^{4}$ Trained research

BMF 1993:306:249-5 nurses $(\mathrm{JH}, \mathrm{JF})$ visited the homes of principal carers two to four months after the death. They administered a semistructured interview asking carers about what had happened in the four weeks before death.

Patients were excluded if they had no identifiable principal carer, if they had been admitted to a hospital or hospice seven days or more before death, or were notified to the project more than four months after death.

Interviewed carers had agreed to take part after explanation of the project and knew they could withdraw at any stage. They were told that the information they gave would remain confidential and that no identifiable information would be passed back to the practice.

\section{Results}

A total of 248 patients were notified to the project by 156 practitioners, and we interviewed 207 carers $(83 \%)$. Two principal carers could not be identified, 13 were not available, two did not with to participate, and three were thought by their general practitioner to be unfit for interview. Five patients had been admitted to a hospital or hospice before their death and 16 were notified outside the time limit.

Of the 207 patients, 124 were male and 83 female. Patients were predominantly elderly (46 aged $<60$ years, 132 aged $60-80$, and 29 aged $>80$ ). Carers were generally younger ( 88 aged $<60,110$ aged $60-80$, and nine aged $>80$ ). Male carers were husbands (43), sons (9), and brothers (3). Female carers comprised wives (90), daughters (41), sisters (7), mothers (6), and friends (5) with one matron, one neighbour, and one partner. All but eight carers were closely related to the patient. During the terminal illness almost half the patients were helped by a daughter (52) or a son (48) in addition to the principal carer. The distribution of cancer types in the sample matched national figures, 5 the most common being cancers of the lung, large bowel, and breast.

\section{SOURCES OF SUPPORT}

The 207 households received professional support from general practitioners (206), district nurses (172), other nurses (Macmillan nurses 25, Marie Curie nurses 21 , night nurses 61 ), health visitors (1), social workers (28), occupational therapists or physiotherapists (22), acupuncturists (2), dietitians (1), and home helps (25). Carers also received support from the clergy (57), voluntary organisations (20), cancer organisations (4), and neighbours and friends (82).

Carers were asked whether they knew how to contact professional support day and night (address, telephone number), and how many times they had difficulty getting help when it was urgently needed (table I). Carers had difficulty in 15 out of 177 urgent calls.

Two thirds of the carers did not need help or were satisfied with the support they received with shopping (87), meals (30), cleaning (43), and laundry (43). A
District nurse $(n=172)$

Other nurses $(n=107)$

Health visitor $(n=1)$

Social worker $(n=28)$

Therapist $(n=22)$
No accessible No of times No of times had difficulty

$\begin{array}{rrr}205 & 128 & 11 \\ 134 & 34 & 3 \\ 72 & 15 & 1 \\ 1 & 0 & \\ 5 & 0 & \\ 2 & 0 & \end{array}$


third (68) would have liked more help, and 23 had been unaware that domestic help was available. Twenty nine carers said they would have liked help during the night and 35 mentioned the need for equipment such as commodes, mattresses, and incontinence pads. Many carers commented that earlier provision of such support might have prevented them becoming exhausted.

One hundred and twenty four carers were given no advice about obtaining financial help. Eleven carers learnt after the patient died of benefits they could have had. Of 59 carers who applied for benefit, three were refused, two had benefit withdrawn after being granted it, and 25 received the first benefit after the patient had died. No information about possible support from local or national cancer charities was given to 174 carers.

\section{COPING WITH CARING}

Difficulties in coping with the patient's symptoms was a cause of distress to some carers. Pain was relieved more effectively than any of the other 11 commonest symptoms (table II). Of the 207 patients, 61 had no pain, 138 had pain which was very well or moderately well relieved, and eight obtained no relief. Three of these eight had refused all analgesia. In the week before death 181 patients had experienced no pain or only mild discomfort. However, more than $25 \%$ of patients had no relief for nausea and vomiting, dyspnoea, dysphagia, and confusion.

TABLE II-Symptoms and symptom control in terminally ill cancer patients cared for at home

\begin{tabular}{lcccc}
\hline & & \multicolumn{3}{c}{ No of patients obtaining: } \\
\cline { 3 - 5 } $\begin{array}{c}\text { No of patients } \\
\text { with symptoms } \\
(\mathrm{n}=207)\end{array}$ & $\begin{array}{c}\text { Very good } \\
\text { relief }\end{array}$ & $\begin{array}{c}\text { Moderate } \\
\text { relief }\end{array}$ & $\begin{array}{c}\text { No } \\
\text { relief }\end{array}$ \\
\hline Weakness & 149 & 2 & 40 & 107 \\
Pain & 146 & 96 & 42 & 8 \\
Anorexia & 144 & & 46 & 98 \\
Weight loss & 128 & 2 & 47 & 79 \\
Constipation & 90 & 39 & 43 & 8 \\
Insomnia & 89 & 15 & 58 & 16 \\
Nausea & 81 & 21 & 39 & 21 \\
Dyspnoea & 69 & 20 & 21 & 28 \\
Vomiting & 67 & 19 & 31 & 19 \\
Bedsores & 63 & 12 & 48 & 3 \\
Dysphagia & 62 & 6 & 15 & 41 \\
Confusion & 51 & 3 & 23 & 25 \\
\hline
\end{tabular}

Most carers also developed symptoms during the terminal phase: 90 had had sleep problems, 82 had lost weight, and 60 said they had been nervous and anxious. Only 48 had not had one or more of these symptoms.

Psychological and emotional support were estimated by the extent to which carers had been provided with information, whether the professionals had had time to listen and had seemed to care, whether the carers had been taught how to cope with simple nursing tasks, and whether the carer had been supported in bereavement.

Of 181 carers, 112 thought they had been given all the information they needed about the illness and 61 considered they had been given adequate financial information. Only 28 were satisfied with the information provided about other sources of support.

Most carers thought that the health and social work professionals had had time to listen (198 responded yes, 8 no, and 1 no comment) and were caring (191 responded yes, 13 no, 3 no comment). When asked directly which type of professional had provided this support carers stated that nearly $20 \%$ of nurses and doctors and $40 \%$ of social workers had not done so.

Of the 207 carers, 173 performed simple nursing procedures daily, 148 carers often doing so both day and night. Seventy of these frequent carers were nurses or trained in first aid. Of the 103 with no nursing training, 48 had received some practical instructions during the terminal illness from visiting nurses and 55 had not.
During the first month after the death 160 carers received home visits. Visits were made by 130 general practitioners, 96 district nurses, 42 other nurses, nine social workers, three health visitors, and one therapist.

\section{OVERALL OUTCOME}

During the four weeks before the patient's death 22 carers had been unhappy or very unhappy, 67 reasonably content, and 108 content or very content. The overall services and support they had received were judged poor by two, moderate by eight, good by 45 , and excellent by 150 .

\section{Discussion}

Historically one of the most distressing features of terminal care at home for both cancer patients and their carers has been the failure to control pain. In 1973 Cartwright et al reported "very distressing symptoms," among which pain was prominent. ${ }^{\circ}$ In 1978 Parkes found nearly half of terminally ill cancer patients at home had severe or very severe pain. ${ }^{7}$ Moreover 28\% "suffered severe and mostly unrelieved pain during the final phase at home" despite drugs. In 1984 Wilkes reported that relatives considered that $54 \%$ of terminally ill patients had ineffectively controlled pain. ${ }^{8}$ By contrast we found that although 146 $(70 \%)$ of patients experienced pain, only eight $(4 \%)$ had had no relief. Moreover during the week before death $87 \%$ had had no pain or only mild discomfort. Figures for pain relief in recent surveys vary. ${ }^{9 \cdot 11}$ The encouraging feature of this study is that improved pain relief had been provided by primary care teams augmented in a few cases by specialist nurses. Nevertheless, control of other symptoms remained poor.

Another deficiency previously reported was the difficulty carers met in "getting any trusted familiar out-of-hours advice." Higginson et al also refer to difficulties in getting doctors to visit at home. In this study out of hours contact points were known for $78 \%$ of district nurses and over $99 \%$ of general practitioners. It was rare for carers to have difficulty in obtaining help when the need was urgent.

The most notable deficit of care was lack of information about financial benefits and sources of help outside the health service. Devonshire has several active local and national cancer charities able to provide help with minimum delay. Yet $84 \%$ of carers had not been advised of their existence. Delays in delivery of domestic help were also found. Although most carers were satisfied with the support they eventually received, many were exhausted by the time it arrived.

Another unrecognised need was that most carers themselves experienced physical symptoms during the terminal illness. They were often reluctant to mention these to doctors, explaining to the interviewers that their own problems weren't bad enough to bother the doctor or that the doctors and nurses would ask about them if it was important. Clearly many carers believed the doctors and nurses would know about their problems without being told.

Practical nursing support was also lacking for most of the carers involved in daily care. Carers recalled feeling useless and helpless because they were not taught what to do.

\section{CONCLUSIONS}

Although care has improved greatly over the past 10 years, deficits still exist-namely, lack of early domestic support, lack of financial advice, lack of information about resources outside the health service, and lack of practical support. Many doctors and nurses did not seem to recognise the importance of controlling symptoms other than pain and were unaware of the problems of the carers. 
Some of these deficits relate to service provision but for most the remedy lies with the health professionals. The challenge for educators is to stimulate and motivate colleagues to practise patient centred medicine in this difficult and demanding field.

We thank the Cancer Research Campaign for funding this project. We also thank Heather Hutchinson, our secretary, Dr T A Dudgeon for his constructive comments, and the carers and practices for their cooperation.

1 Standing Medical Advisory Committee. Terminal care: report of a working group. London: HMSO, 1980.

2 King Edward's Hospital Fund for London and the National Association of

Health Authorities. Care of the dying: a guide for health authorities. Birming $\mathrm{NAF}$
3 Jones RVH. Primary health care: What should we do for people dying at home with cancer? Eur 7 Cancer Care 1992;1:9-11.

4 Jones RVH, Dudgeon TA. Time between presentation and treatment of six common cancers: a study in Devon. Br $\mathcal{F}$ Gen Pract 1992;42:419-22.

5 Cancer Research Campaign. Mortality-UK. London, CRC: 1989. (Factsheet 3.1.

6 Cartwright A, Hockey L, Anderson JL. Life before death. London: Routledg and Kegan Paul, 1973.

7 Parkes CM. Home or hospital? Terminal care as seen by surviving spouses. J R Coll Gen Pract 1978;28:19-30.

8 Wilkes E. Dying now. Lancet 1984;i:950-2.

9 Higginson I, McCarthy $M$. Measuring symptoms in terminal cancer: are pain and dyspnoea controlled? $\mathcal{I} R$ Soc Med 1989;82:2264-7.

10 Herd EB. Terminal care in a semi-rural area. Brf Gen Pract 1990;40:248-51.

11 Sykes NP, Pearson SE, Chell S. Quality of care of the terminally ill: the carer's perspective. Palliative Medicine 1992;6:227-36.

12 Higginson I, Wade A, McCarthy M. Palliative care: views of patients and families. $B M \mathcal{F}^{\prime}$ 1990;301:277-81.

(Accepted 20 November 1992)

\section{The Future of FHSAs}

\section{Commissioning for quality}

\section{Graham Butland}

This is the fourth in a series of articles on the future of family health services authorities
Essex Family Health Services Authority, Clacton on Sea, Essex CO15 6QD

Graham Butland, chief executive

Series editor: Dr Andrew Harris
Primary health care is now high on the health agenda. The decision, taken immediately after the general election, not to move quickly to merge family health services authorities with district health authorities reflected a feeling at the centre that the development of primary care, and in particular general practice, is a major task that requires the undivided attention of one agency.

The general acceptance of the need to transfer resources from the acute sector to primary health care masks the real problems that exist in primary care and in general practice. Primary health care is the least organised part of the NHS, relying as it does on an outmoded system of organisation that has changed little since the inception of the NHS in 1948. While the rest of the NHS moves towards a contracting system based on the health needs of local population, family health services remain wedded to the blunderbuss of national contracts.

The inflexibility of this approach is being highlighted in many ways. The Tomlinson report into London's health services was critical of the current contract. "Many of the problems we have identified stem from this. In particular we see little direct local management accountability for services delivered and for

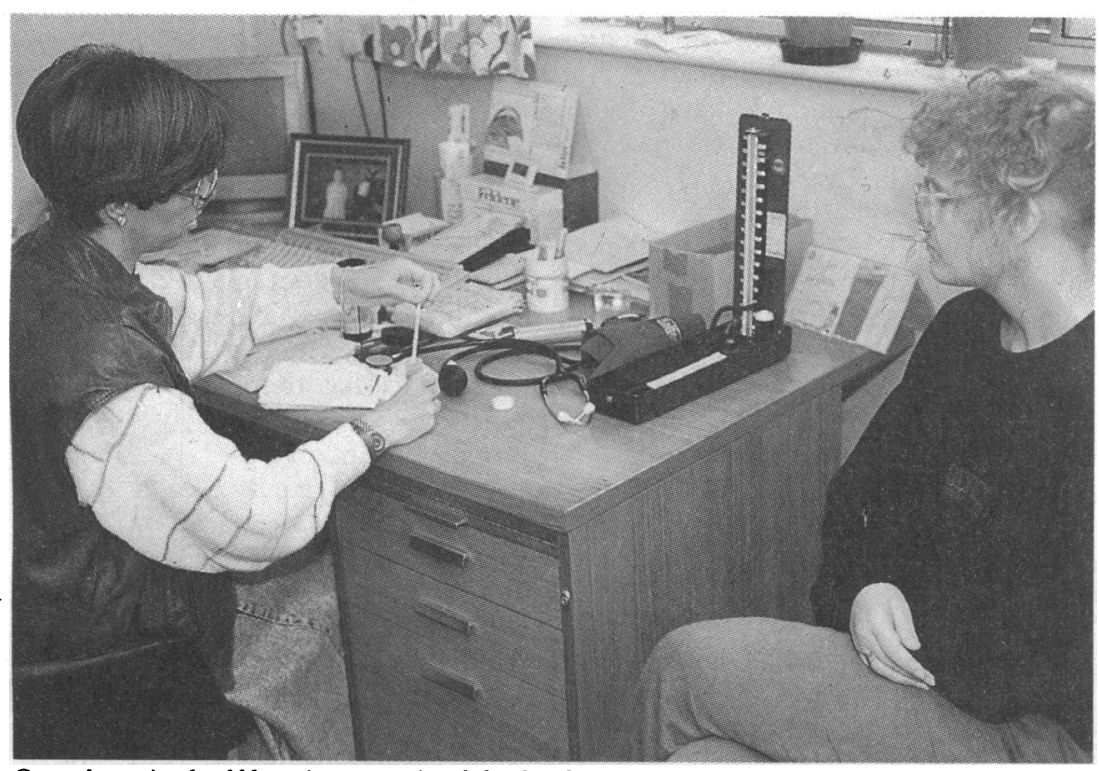

General practice should have its core services defined and enter into separate contracts for extra services resources consumed in the General Medical Services."

Another issue identified by Tomlinson as a constraint on the development of general medical services by family health services authorities is the fact that they "have no management control over the allocation within their areas of the most important resource: skilled manpower, in the form of GPs." Tomlinson questions the role of the medical practices committee and recommends that within the London primary care development zones the medical practices committee should devolve to authorities the responsibility for deciding how the general practitioner staffing might best be organised. Such a recommendation might equally apply to the rest of the country.

Similarly, the introduction of a patient's charter for primary care has run into difficulties where the desires of its authors confront the regulatory minefield surrounding family health services. The complaints procedure is an excellent example of the way in which the current bureaucratic system is incompatible with the concept of a patient's charter.

\section{Primary health care teams}

If family health services authorities are to be able to adapt a truly consumer oriented approach to services there must be a radical change in the current method of contracting, and also in the way in which general practice is organised. The current situation of contracts with individual doctors must be replaced at the very least by contracts with practices but in the longer term by contracts with multidisciplinary primary health care teams.

The concept of primary health care teams has been with us for many years, but in reality there are precious few examples of them effectively existing in practice. The fragmentation of services must be addressed if primary health care is to play a more important part in the future. The rethink that is taking place about the desirability of incorporating community services in whole district NHS trusts is to be welcomed.

The fact that the present general practitioner contract does not specify in detail what services are covered by it makes planning the delivery of primary health care services difficult. Just as there are core services specified in contracts with hospitals, so general practice should have its core services defined. These would be services that all practices in contract with the NHS would be expected to deliver. This would enable practices wishing to offer services in excess of the 